\title{
REVIEW
}

\section{Inflammatory gene polymorphisms and ischaemic heart disease: review of population association studies}

\section{F Andreotti, I Porto, F Crea, A Maseri}

Heart 2002;87:107-112

Inflammation and genetics are both prominent mechanisms in the pathogenesis of atherosclerosis and arterial thrombosis. Accordingly, a number of population studies have explored the association of ischaemic heart disease with gene polymorphisms of the inflammatory molecules tumour necrosis factors (TNF) $\alpha$ and $\beta$, transforming growth factors (TGF) $\beta 1$ and 2 , interleukin (IL) 1 and its receptor antagonist (IL 1 ra), CD 14 (the receptor for lipopolysaccharide), P and E selectins, and platelet endothelial cell adhesion molecule (PECAM) 1. Although they are very preliminary and partly conflicting, the data provide some evidence that alterations in the genetics of the inflammatory system may modify the risk of ischaemic heart disease.

See end of article for authors' affiliations

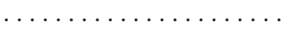

Correspondence to: Dr F Andreotti, Cardiology, Catholic University, 00168 Rome, Italy:

felicita.andreotti@iol.it

Accepted 26 September 2001
$\mathrm{R}$ ecent attention has focused on the inflammatory component of atherogenesis and acute ischaemia. ${ }^{12}$ Indeed, atherosclerosis is now described as an inflammatory disease ${ }^{1}$ and flared plaque inflammation is considered a cause of intimal erosion and rupture and therefore of acute ischaemia. ${ }^{2}$ Studies in vitro and in experimental animals are supported by the clinical finding of increased inflammatory markers in patients with chronic stable angina, ${ }^{3}$ severe unstable angina, and acute myocardial infarction $^{2}$ and by the predictive value of such markers for subsequent coronary events. ${ }^{2}$

Because genetic traits contribute significantly to the global risk of ischaemic heart disease (IHD), ${ }^{2}$ a number of studies have now addressed the hypothesis that variations in the genetics of the inflammatory system may increase the risk of disease. Differences in the genetic regulation of inflammatory processes might explain why some people but not others develop the disease and why some develop a greater inflammatory response than others. ${ }^{2}$

Through a Medline search of the literature published from 1992 to July 2001, we reviewed the existing literature linking IHD to gene variants of the inflammatory system, using "inflammation", "polymorphisms", "atherosclerosis", and "myocardial infarction" as keywords. We subsequently focused on cytokines, cell receptors, their antagonists, and adhesion molecules. Bibliographies in the articles provided further references. Relevant journals were also hand searched. With a few exceptions, only case control studies of $\geqslant 100$ cases were included. Whenever possible, studies of atherosclerosis or generic IHD were distinguished from those of acute coronary syndromes (table 1 versus table $2^{4-26}$ ), on the assumption that the inflammatory process may differ in the two settings.

\section{TUMOUR NECROSIS FACTOR $\alpha$}

Tumour necrosis factor (TNF) $\alpha$ is a pleiotropic proinflammatory cytokine produced mainly by activated macrophages ${ }^{27}$ (fig 1). Major effects on the cardiovascular system include increased expression of adhesion molecules and human leucocyte antigen proteins, release of endothelial cytokines and nitric oxide, enhanced vascular permeability, negative inotropism, reduced lipoprotein lipase activity, increased hepatic fatty acid synthesis, involvement in obesity related insulin resistance, and prothrombotic effects (through enhanced expression of plasminogen activator inhibitor 1 and von Willebrand factor and through suppression of the anticoagulant protein C). ${ }^{27} \mathrm{TNF}$ $\beta$ is synthesised primarily by $\mathrm{T}_{\text {cells }}{ }^{27}$ ( fig 1 ).

\section{TNF $\alpha$ polymorphisms}

The human TNF $\alpha$ gene maps to chromosome 6 (p21.1-21.3) within the human leucocyte antigen complex. ${ }^{27}$ Data in vitro indicate that a $G(-308) \mathrm{A}$ transition modulates transcription. ${ }^{28}$ Herrmann et $a l^{4}$ screened the coding region of the gene and 1053 base pairs upstream of the transcription starting site: five polymorphisms, including $\mathrm{G}(-308) \mathrm{A}$, were identified and assessed in the ECTIM (étude cas-témoin de l'infarctus du myocarde), a study of approximately 650 male survivors of myocardial infarction (mean age 54 years) and 750 control subjects from four regions of France and Northern Ireland. No association was found with either myocardial infarction or coronary artery disease. ${ }^{4} \mathrm{~A}$ recent study of 148 survivors of myocardial infarction ( $<55$ years) and 148 control subjects confirmed the lack of association between $-308 \mathrm{~A}$ and infarction. ${ }^{5}$ In a study of 674 patients with angiographically confirmed coronary artery stenoses and 1059 controls, the $-308 \mathrm{~A}$ allele again was not associated with the presence or number of stenosed arteries. ${ }^{16}$ Finally, a recent necropsy series of 700 men also found no significant associations

Abbreviations: $\mathrm{Cl}$, confidence interval; ECTIM, étude cas-témoin de l'infarctus du myocarde; IHD, ischaemic heart disease; IL, interleukin; IL 1 ra, interleukin 1 receptor antagonist; OR, odds ratio; PECAM, platelet endothelial cell adhesion molecule; TGF, transforming growth factor; TNF, tumour necrosis factor; VNTR, variable number of tandem repeats 
Table 1 Summary of case control studies linking inflammatory gene polymorphisms to myocardial infarction

\begin{tabular}{|c|c|c|c|}
\hline Investigated gene & Number of patients & Main findings & Authors, year \\
\hline TNF $\alpha$ & 641 men & Various polymorphisms not associated with $\mathrm{MI}$ & Herrmann et al, $1998^{4}$ \\
\hline TNF $\alpha$ and $\beta$ & 148 & Various polymorphisms not associated with $\mathrm{Ml}$ & Padovani et al, $2000^{5}$ \\
\hline \multirow[t]{2}{*}{ TGF $\beta 1$} & 563 men & Pro ${ }^{25}$ associated with $\mathrm{Ml}(\mathrm{p}<0.05)$ but with regional variations & Cambien et al, $1996^{\circ}$ \\
\hline & 234 men & Leu $^{10}$ associated with $\mathrm{MI}$ in Japanese patients (OR=3.5, $\mathrm{p}<0.0001$ ) & Yokota et al, $2000^{7}$ \\
\hline \multirow[t]{2}{*}{ IL-1 ra } & 74 & Intron 2 VNTR alleles not associated with MI & Manzoli et al, $1999^{\circ}$ \\
\hline & 148 & Intron 2 VNTR alleles not associated with MI & lacoviello et al, $2000^{\circ}$ \\
\hline \multirow[t]{4}{*}{ CDI4 } & 178 men & $-260 \mathrm{~T}$ associated with first $\mathrm{MI}(\mathrm{OR}=1.8, \mathrm{p}=0.0005)$ & Hubaceck et al, $1999^{10}$ \\
\hline & 81 men & $-260 \mathrm{~T}$ associated with first $\mathrm{MI}$ in Japanese $(\mathrm{OR}=3.8, \mathrm{p}=0.004)$ & Shimada et al, $2000^{11}$ \\
\hline & $173 *$ & $\begin{array}{l}-260 T \text { associated with } \mathrm{Ml} \text { in "low risk" patients undergoing } \\
\text { angiography }(O R=1.6, p<0.05)\end{array}$ & Unckelbach et al, $1999^{12}$ \\
\hline & $387 \dagger$ men & $-260 \mathrm{~T}$ not associated with incident $\mathrm{MI}$ & Zee et al, $2001^{13}$ \\
\hline P selectin & 650 men & Pro $^{715}$ protective against $\mathrm{MI}(\mathrm{OR}=0.7, \mathrm{p}<0.02)$ & Herrmann et al, $1998^{14}$ \\
\hline E selectin & 650 men & $\operatorname{Arg}^{128}$ not associated with $\mathrm{Ml}$ & Herrmann et al, $1998^{14}$ \\
\hline PECAM 1 & $1170 *$ & $\mathrm{Val}^{125}$ not associated with $\mathrm{Ml}$ & Gardemann et al, $2000^{15}$ \\
\hline
\end{tabular}

IL 1 ra, interleukin 1 receptor antagonist; MI, myocardial infarction; OR, odds ratio; PECAM, platelet endothelial cell adhesion molecule; TGF, transforming growth factor; TNF, tumour necrosis factor; VNTR, variable number of tandem repeats.

*Healthy control subjects not included. †Prospective study.

between -308A and either frequency of healed myocardial infarction and coronary thrombosis or number and severity of coronary stenoses. ${ }^{17}$

\section{TNF $\beta$ Asp26Thr polymorphism}

The TNF $\beta$ gene is close to and strongly linked with the TNF $\alpha$ gene. ${ }^{27}$ Braun et al ${ }^{18}$ investigated a functional polymorphism (Asp26Thr, which correlates with TNF $\beta$ production) in 199 men with IHD (defined as $\geqslant 50 \%$ diameter stenoses) and 81 control subjects. No association was found with the presence or extent of coronary disease or with previous infarction although, in the patient group, heterozygosity for $\mathrm{Thr}^{26}$ was associated with hyperinsulinaemia. ${ }^{18}$ Another variant (A252G in intron 2), which correlates with increased TNF $\beta$ concentrations, was also not associated with myocardial infarction. ${ }^{5}$ Thus, the TNF polymorphisms explored so far do not appear to be linked to IHD.

\section{TRANSFORMING GROWTH FACTORS $\beta 1$ AND $\beta 2$}

Transforming growth factor (TGF) is expressed by a wide range of cells, including platelets, endothelial, haematopoietic, and connective tissue cells ${ }^{29}$ (fig 1). Major functions attributed to TGF $\beta 1$ are immunosuppression, reduction of inflammation, promotion of wound healing, and regulation of cell proliferation, cell migration, cell differentiation, and extracellular matrix production. ${ }^{29}$ Various studies suggest an inverse relation between TGF $\beta 1$ and IHD, ${ }^{29}$ while others suggest a role in vascular restenosis. ${ }^{30}$

\section{TGF $\beta 1$ polymorphisms}

The human TGF $\beta 1$ gene on chromosome 19 (q13.1-13.3) ${ }^{31}$ was screened in the ECTIM. ${ }^{6}$ The prevalence of the Arg25Pro $(\mathrm{G} 74 \mathrm{C})$ variant was increased in patients from Belfast $(p<0.01)$ and Strasbourg $(p<0.05)$ but not in the two other populations (Lille and Toulouse), although the overall difference was significant $(p<0.05)$. Among the 374 French patients who underwent coronary angiography, no association was seen between Pro $^{25}$ and number of $\geqslant 50 \%$ diameter stenoses. Other polymorphisms, including Leu 10Pro (T29C), were not associated with disease. ${ }^{6}$ The latter was evaluated in 315 Japanese survivors of myocardial infarction (234 men) and 591 healthy control subjects. ${ }^{7}$ On multivariate analysis there was a higher prevalence of the $\mathrm{T}$ allele in male patients than in male controls (TT + TC versus CC: odds ratio (OR) $3.5,95 \%$ confidence interval (CI) 2.0 to $6.3, \mathrm{p}<0.0001$ ) but not in women. ${ }^{7}$ Controls (men and women) with the CC genotype had significantly higher serum TGF $\beta 1$ concentrations. ${ }^{\top}$

Table 2 Summary of case control studies linking inflammatory gene polymorphisms to atherosclerosis

\begin{tabular}{|c|c|c|c|}
\hline Investigated gene & Number of patients & Main findings & Authors, year \\
\hline \multirow[t]{3}{*}{ TNF $\alpha$} & 641 men & Several polymorphisms not associated with severity or extent of CAD & Herrmann et al, $1998^{4}$ \\
\hline & 674 & -308 A not associated with CAD & Francis et al, $1999^{16}$ \\
\hline & 700 men (autopsy) & $-308 \mathrm{~A}$ not associated with CAD & Keso et al, $2001^{17}$ \\
\hline TNF $\beta$ & 199 men & $\mathrm{Thr}^{26}$ not associated with CAD & Braun et al, $1998^{18}$ \\
\hline \multirow[t]{3}{*}{ TGF $\beta 1$} & 374 men & Several variants not associated with CAD & Cambien et al, $1996^{\circ}$ \\
\hline & $655^{*}$ & $\begin{array}{l}\text { Several polymorphisms not associated with coronary artery diameter } \\
\text { stenoses } \geqslant 30 \%\end{array}$ & Syrris et al, $1998^{19}$ \\
\hline & 371 * & $-509 T$ not associated with CAD & Wang et al, $1998^{20}$ \\
\hline TGF $\beta 2$ & 101 & TGF $\beta 2$ variant not associated with IHD & Biggart et al, $1998^{21}$ \\
\hline \multirow{3}{*}{ IL 1 system } & 674 & IL $1 \alpha(-889)$ and IL $-1 \beta(-511$ and +3593) not associated with CAD & Francis et al, $1999^{16}$ \\
\hline & 674 & $\begin{array}{l}\text { IL } 1 \text { ra intron } 2 \text { VNTR allele } 2 \text { associated with SVD (OR=2.8, p<0.005) } \\
\text { but not with MVD }\end{array}$ & Francis et al, $1999^{16}$ \\
\hline & 1850 & IL $1 \mathrm{ra}+8006 \mathrm{C}$ (exon 2) associated with protection against restenosis & Kastrati et al, $2000^{22}$ \\
\hline CD14 & 1053 & $-159 T$ not associated with CAD & Unckelbach et al, $1999^{12}$ \\
\hline \multirow[t]{2}{*}{ E selectin } & 97 and 99 & $\begin{array}{l}\mathrm{Arg}^{128} \text { and Phe } \mathrm{P}^{554 \mathrm{~T}} \text { associated with severe coronary or peripheral } \\
\text { atherosclerosis } \leqslant 50 \text { years }(p=0.02)\end{array}$ & Wenzel et al, $1994,{ }^{23} 1996^{24}$ \\
\hline & $82^{*}$ & $\operatorname{Arg}^{128}$ associated with $\geqslant 50 \%$ coronary stenoses $(p<0.05)$ & Ye et al, $1999^{25}$ \\
\hline \multirow[t]{2}{*}{ PECAM 1} & 98 & $\mathrm{Val}^{125}$ and $A s n^{563}$ associated with $C A D \leqslant 50$ years $(p<0.05)$ & Wenzel et al, $1999^{26}$ \\
\hline & $2500^{*}$ & $\begin{array}{l}\mathrm{Val}^{125} \text { associated with CAD in "low " versus "high risk" patients (RR=1.5, } \\
p=0.035 \text { ) }\end{array}$ & Gardemann et al, $2000^{15}$ \\
\hline
\end{tabular}

CAD, coronary artery disease; IHD, ischaemic heart disease; IL 1, interleukin 1; MVD, multivessel coronary disease; OR, odds ratio; RR, relative risk; SVD, single vessel coronary disease.

*Healthy control subjects not included. 


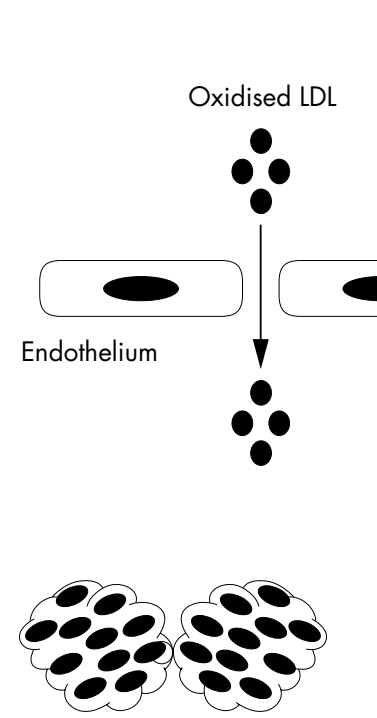

Foam cells

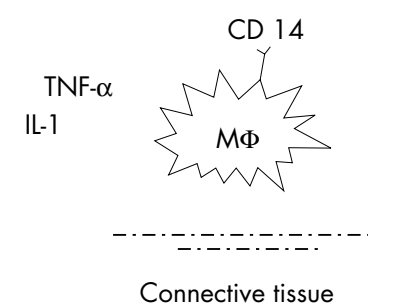

Connective tissue

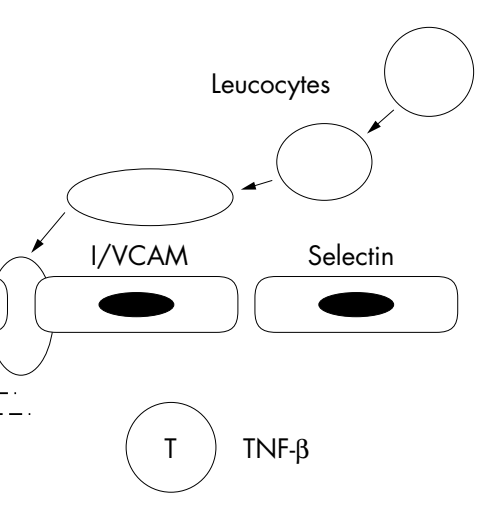

T

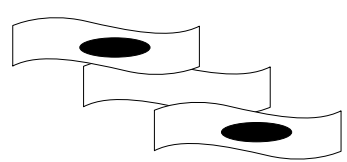

Smooth muscle cells
Figure 1 Simplified representation of the role of inflammatory molecules in atherogenesis. Injured endothelial cells (for example, by oxidised low density lipoprotein (LDL), cytokines, or lipopolysaccharide) produce cytokines (for example, interleukin (IL) 1), which stimulate the expression of adhesion proteins on the endothelial surface (for example, selectins and cell adhesion molecules). The latter recruit circulating leucocytes into the subendothelial space. Further cytokine release by infiltrated monocyte/macrophages $(M \Phi)$ and $T$ lymphocytes promotes the formation of foam cells and the migration of smooth muscle cells from the media. The proinflammatory effects of IL 1 and tumour necrosis factor (TNF) are counterbalanced by the modulatory effects of transforming growth factor (TGF) produced by connective tissue cells. ICAM, intercellular adhesion molecule; VCAM, vascular cell

adhesion molecule.
Syrris et al $^{19}$ also screened the TGF $\beta 1$ gene and assessed five polymorphisms (including Arg25Pro and Leu10Pro) in 655 patients with IHD (defined as $>30 \%$ diameter stenoses, without reference to previous acute events) and 244 patient controls. No significant difference in the distribution of any of these polymorphisms or associated haplotypes was found between patients and control subjects. ${ }^{19}$ Another common variant in the TGF $\beta 1$ promoter, a $C$ to $T$ transition at nucleotide -509 , assessed in 371 patients also was not associated with the number of $\geqslant 50 \%$ coronary stenoses. ${ }^{20}$ In summary, the data on TGF $\beta 1$ are somewhat controversial, with the majority of studies showing no association with IHD; there is, however, a suggestion that certain polymorphisms may increase the risk of infarction within specific ethnic groups.

\section{TGF $\beta 2$ polymorphism}

Biggart $e t a l^{21}$ evaluated a TGF $\beta 2$ gene variant in 101 patients with generic IHD (men $<55$ years and women $<60$ years of age) and in 100 control subjects with angiographically confirmed normal coronary arteries. The variant was not associated with IHD.

\section{INTERLEUKIN 1 SYSTEM}

Interleukin (IL) 1, released by macrophages, platelets, and injured endothelium (fig 1), promotes the interaction of endothelial cells with circulating leucocytes, ${ }^{32}$ induces the activation and proliferation of monocytes/macrophages, and stimulates smooth muscle cell mitogenesis and the synthesis of plasminogen activator inhibitor $1 .{ }^{32}$ It is believed to play a key part in atherogenesis and thrombosis. ${ }^{32}$ The IL 1 receptor antagonist (IL Ira) is a soluble antagonist of IL 1 that binds without activity to the IL 1 signalling receptor type I. $^{32}$ Several autoimmune and inflammatory diseases have been associated with a variable number of tandem repeats (VNTR) of an 86 base pair sequence in intron 2 of the IL lra gene. ${ }^{8}$ There are five alleles for this polymorphism corresponding to two, three, four, five, and six repeats; allele 2 (IL lra*2, corresponding to two repeats) has been associated with the severity and extent of diseases in vivo ${ }^{8}$ and with enhanced production of IL $1 \beta$ in vitro. $^{33}$

\section{Polymorphisms of the IL 1 system}

The human genes for IL $1 \alpha$, IL $1 \beta$, their receptors, and IL Ira are clustered on chromosome 2 (q14-q21). ${ }^{8}$ In an English study, ${ }^{16}$ allele frequencies of IL $1 \alpha(-889)$, IL $1 \beta(-511$ and
+3593), and the IL 1ra intron 2 VNTR were measured in 827 healthy blood donors, in 232 patients with angiographically unobstructed coronary arteries (patient controls: 102 from London and 130 from Sheffield), and in 674 patients with single vessel disease ( 57 and 98 , respectively) or multivessel disease (191 and 328, respectively). The IL 1 gene variants were not significantly associated with the presence or extent of disease, whereas homozygosity for IL $1 \mathrm{ra}^{\star} 2$ was significantly associated with single vessel disease with an OR of 2.8 when data from London and Sheffield were pooled (95\% CI 1.4 to 5.7, $\mathrm{p}=0.005$ ). Allelic frequencies in patients with multivessel disease were similar to those of healthy and patient controls. To explain the association with single but not with multivessel disease, the authors suggest that the IL Ira VNTR may act as a "disease modifying" rather than a causative polymorphism. $^{16}$ In a cohort of 1850 patients another polymorphism in strict linkage disequilibrium with the IL 1ra*2 allele $(+2018$ in exon 2$)$ was recently associated with protection from coronary restenosis after stenting. ${ }^{22}$

Two subsequent Italian studies found no significant association between IL 1ra*2 and infarction: the first compared 115 patients with IHD (74 with first myocardial infarction) with 80 matched controls $^{8}$ and the second compared 148 infarct survivors (men $\leqslant 45$ years and women $\leqslant 50$ years of age) with 153 matched controls. ${ }^{9}$ In the latter study, the frequencies of IL lra* 2 were 0.25 in survivors versus 0.25 in controls and those of IL- $1 \mathrm{ra}^{*} \mathrm{l}$ were 0.72 versus 0.73 , respectively. Thus, the association between the IL 1 system and atherosclerosis is probably complex and may vary with clinical phenotype and extent of disease.

\section{14}

CD surface molecules mediate cell activation and signalling. In particular, CD14 on blood monocytes mediate monocyte/ macrophage activation by lipopolysaccharide. ${ }^{34}$ Lipopolysaccharide bound to CD14 may contribute to atherogenesis by stimulating macrophages to produce TNF $\alpha$, IL 1, IL 6, IL 8, IL 12, interferon $\gamma$, migration inhibitory factors, chemokines, eicosanoids, and reactive oxygen species, which in turn stimulate the production of a second wave of chemokines, cytokines, and adhesion and signalling molecules ${ }^{35}$ (fig 1). The mature CDI4 protein is present in two isoforms: membrane bound and soluble. ${ }^{34}$ Endothelial and smooth muscle cells are activated by soluble CDI4. ${ }^{36}$ 


\section{CD14 polymorphisms}

The human CD14 gene maps to chromosome $5 .{ }^{34}$ Hubaceck et $a l^{10}$ investigated a $C$ to $\mathrm{T}$ transition at nucleotide -260 in 178 men who suffered a first myocardial infarction before 65 years of age and 135 controls. The frequency of $-260 \mathrm{~T}$ was $0.49 \mathrm{in}$ patients and 0.35 in controls (OR 1.8, 95\% CI 1.3 to 2.5 , $\mathrm{p}=0.0005)$; moreover, CD14 receptor density was higher among TT homozygotes than among the other two genotypes $(\mathrm{p}<0.003) .{ }^{10}$ The same dimorphism was investigated by Shimada et $l^{11}$ in 211 Japanese subjects ( 128 patients with $>50 \%$ stenosis in at least one epicardial artery and 83 healthy controls). In this group, the $\mathrm{T}$ allele was strongly associated with myocardial infarction, as TT homozygosity carried an adjusted OR of 3.8 (CI 1.79 to $6.98, p=0.0001$ ) among the 81 patients with infarction, whereas no association was seen in the 47 patients with stable angina. ${ }^{11}$

Unckelbach et al ${ }^{12}$ studied this polymorphism in 2228 men undergoing coronary angiography (mean age 62 years). A healthy control group was not investigated. Overall, no significant association was found between this variant and previous myocardial infarction or severity and extent of coronary disease. However, in the 173 normotensive, nonsmoking patients ( 64 with prior infarction and 109 without) a small increase in the risk of infarction was detected among TT homozygotes (OR 1.6, 95\% CI 1.0 to $2.4, \mathrm{p}<0.05$ ). ${ }^{12}$ The association was stronger in a smaller group of 76 "low risk" patients ( 30 with previous infarction) older than 62 years (OR $3.8,95 \%$ CI 1.6 to $9.0, \mathrm{p}<0.01){ }^{12}$

Recently, Zee et al, ${ }^{13}$ in a nested case control study of 387 patients with incident myocardial infarction and an equal number of age and smoking matched control subjects from the Physicians' Health Study, questioned this association because no increased risk was found with the $\mathrm{T}$ allele, even in the homozygous state. Overall, these conflicting data may be explained by a number of reasons: the use of subgroup analyses, racial dishomogeneity, and the different definition of phenotype, as infarction at a young age "out of the blue" differs phenotypically from an infarct in an elderly person with multiple risk factors. Further studies should clarify whether the $-260 \mathrm{~T}$ allele of CDI4 significantly increases the risk of myocardial infarction among low risk caucasians and the Japanese.

\section{ADHESION PROTEINS}

Adhesion of circulating cells to the arterial surface is among the first detectable events in atherogenesis. ${ }^{1}$ Selectins on the membrane of monocytes, lymphocytes, and endothelial cells enable white cells to roll along the lumen. ${ }^{37}$ Subsequently, integrins and molecules of the immunoglobulin superfamily (platelet endothelial cell adhesion molecule (PECAM) 1, intercellular adhesion molecule 1 , and vascular cell adhesion molecule 1) on leucocytes and endothelial cells allow white cells to attach firmly to the vessel wall, enabling them to cross it $^{1}$ (fig 1). P selectin (CD62P) is stored in endothelial Weibel Palade bodies and platelet $\alpha$ granules. It appears on the endothelial and platelet surface within minutes after stimulation by IL $1 .{ }^{37}$ Its expression is increased in atherosclerotic plaques $^{38}$ and high plasma concentrations of soluble P selectin are found in patients with unstable angina. ${ }^{39}$ E selectin (CD62E) is transiently expressed on endothelial cells within hours after stimulation by TNF $\alpha$, IL 1 , and lipopolysaccharide. ${ }^{40} \mathrm{~L}$ selectin is constitutively expressed by all leucocytes while PECAM l (CD31) is constitutively expressed by endothelial cells, bone marrow stem cells, platelets, and most circulating leucocytes. ${ }^{41}$ Soluble PECAM 1 is increased in patients with acute myocardial infarction. ${ }^{42}$

\section{P selectin Pro ${ }^{715}$ polymorphism}

Human genes of the selectin family are clustered on the long arm of chromosome 1 (q21-q24). ${ }^{43}$ Thirteen P selectin gene polymorphisms were assessed in the ECTIM. ${ }^{14}$ The Pro ${ }^{715}$ allele of the missense Thr715Pro variant was globally less frequent in patients than in control subjects $(\mathrm{p}<0.002$ and $\mathrm{p}<0.02$ after correction for number of tests), with an OR for infarction of 0.7 (95\% CI 0.5 to 0.9 ). ${ }^{14}$ The lower Pro ${ }^{715}$ frequency among infarct survivors was later confirmed in the ECTIM extension of approximately 600 patients (29\% women) and 600 control subjects from Belfast and Glasgow $(\mathrm{p}=0.054) .{ }^{44}$ The Pro ${ }^{715}$ allele may thus confer protection against myocardial infarction. Functional data on this polymorphism are still unclear. ${ }^{14}$

\section{E selectin polymorphisms}

The E selectin A561C transversion (Ser128Arg) was investigated by Wenzel et al in two studies. ${ }^{23}{ }^{24}$ The variant is thought to modify the molecule's interaction with its ligands. ${ }^{45} \mathrm{~A}$ first study found a higher $\operatorname{Arg}^{128}$ prevalence among 97 patients $\leqslant 50$ years old with severe coronary or peripheral atherosclerosis than among control subjects (allele frequency $0.16 \mathrm{v} 0.09$, $\mathrm{p}=0.02$ ) with a stronger association among the 40 patients who were $\leqslant 40$ years old $\left(\operatorname{Arg}^{128}\right.$ frequency $\left.0.21, p=0.003\right){ }^{23}$ In a second study, a number of polymorphisms of $\mathrm{E}, \mathrm{P}$, and $\mathrm{L}$ selectin and of intercellular adhesion molecule 1 and vascular cell adhesion molecule 1 were assessed in 99 patients (defined as above) and 100 age matched healthy volunteers. ${ }^{24}$ Three E selectin polymorphisms $\left(\mathrm{Arg}^{128}, 98 \mathrm{~T}\right.$, and $\left.\mathrm{Phe}^{554}\right)$ were all significantly associated with early onset atherosclerosis (but without correction for repeated testing). In patients and control subjects, the $\operatorname{Arg}^{128}$ and $98 \mathrm{~T}$ alleles were correlated $(r=0.9, \mathrm{p}<0.001)$ while the frequency of Phe ${ }^{554}$ was $0.06 v$ $0.02(\mathrm{p}=0.02) .^{24}$ A higher frequency of $\operatorname{Arg}^{128}$ was also observed by Ye $e t a^{25}$ among 82 patients with $>50 \%$ diameterstenoses at coronary angiography than among 71 control subjects with normal angiograms $(0.20 v 0.11, \mathrm{p}<0.05)$. In contrast, in ECTIM, $\operatorname{Arg}^{128}$ was not significantly associated with myocardial infarction. ${ }^{14}$ Thus, the E selectin $\operatorname{Arg}^{128}, 98 \mathrm{~T}$, and Phe ${ }^{554}$ alleles may increase the risk of atherosclerosis (but not necessarily of infarction), especially in younger patients.

\section{PECAM 1 polymorphisms}

The human PECAM 1 gene maps to $17 \mathrm{q} 23 .^{46}$ Two polymorphisms, Leu125Val (leading to an immunological difference in the mature protein $\left.{ }^{41}\right)$ and Ser563Asn, were evaluated in 98 patients ( $25-50$ years old) with $\geqslant 50 \%$ coronary artery stenoses and 103 healthy control subjects. ${ }^{26}$ Each variant was more frequent in patients $\left(\mathrm{Val}^{125} 0.65 v 0.51, \mathrm{Asn}^{563} 0.63 v 0.50\right.$, $\mathrm{p}<0.05)$ as was the homozygous combination $\mathrm{Val}^{125} / \mathrm{Asn}^{563}$ $(43 \% \vee 26 \%, \mathrm{p}<0.05){ }^{26} \mathrm{Val}^{125}$ was also investigated by Gardemann et a l $^{15}$ in 2500 German men undergoing diagnostic angiography, grouped according to previous myocardial infarction and the presence and severity of coronary disease. A healthy control group was not included. No evidence of association was found when patients without infarction or significant disease $(n=488)$ were compared with the 1170 patients with previous infarction. Among those with coronary atherosclerosis, however, Val $^{125}$ was more frequent in the non-diabetic and normotensive group $(\mathrm{n}=809, \mathrm{OR}=1.54, \mathrm{p}=0.035) .{ }^{15}$ Thus, as for E selectin, the PECAM 1 Val $^{125}$ and $\mathrm{Asn}^{563}$ alleles may increase the risk of atherosclerosis (but not necessarily of infarction), especially in patients with a low atherosclerotic risk profile.

\section{DISCUSSION \\ Interpretation of population association studies: susceptibility, linkage or stratification?}

The reviewed studies, summarised in tables 1 and 2, are all conceived to show a relation between allele " $\mathrm{A}$ " and a multifactorial disease " $\mathrm{D}$ " whenever the frequency of A differs between patients and control subjects. ${ }^{47}$ An association between A and D, however, may arise for at least three reasons: firstly, A truly affects the susceptibility to D; secondly, A is closely "linked" to the real allele involved in the pathogenesis of $\mathrm{D}$, producing an association known as "linkage disequilibrium"; and thirdly, 
people with D or without D are genetically different and coincidentally also differ in the frequency of A (population stratification) ${ }^{47}$ In the specific case of myocardial infarction, given its high early mortality, possible alleles associated with rapidly fatal infarction may be underestimated among survivors (survival bias). Since the precise role of A in the pathogenesis of D cannot be fully shown by population association studies, these should be considered at best as hypothesis generating. ${ }^{48}$

\section{Small biological effect of single polymorphisms: importance of clinical phenotype}

Several of the reviewed polymorphisms (for example, those for TNF $\alpha$ and $\beta$, TGF $\beta 1$, IL 1ra, CDI4, and E selectin) have been found to be functional-that is, to have direct effects on gene transcription and protein function. However, although allele A may clearly be associated with protein function or concentrations, and protein concentrations with disease, it still may not be possible to relate a given genetic variant to disease, as an individual polymorphism contributes only a fraction to the entire heritable variance in protein concentrations. ${ }^{49}$ Additionally, the small contribution of a single novel polymorphism to the overall risk of a multifactorial disorder such as IHD may be obscured by the presence of one or more dominant classical risk factors. ${ }^{49}$ Several examples from this review support this possibility (for example, the association between CD14 variants and myocardial infarction in normotensive and non-smoking patients or in the generally low risk Japanese population, or between E selectin or PECAM 1 polymorphisms and coronary atherosclerosis in young, nondiabetic, normotensive groups).

Prospectively designed studies and the analysis of haplotypes may overcome some of the limitations of population association studies. ${ }^{50}$ Another way to confront these limits is through careful phenotypic characterisation of patients, since a new genetic risk factor is more likely to emerge within homogeneous groups of patients in whom it has a similar role. Identifying such homogeneous groups may be difficult and may require rigorous control not only of age, sex, race, and ethnic grouping but also of clinical features and biochemical markers linked to specific pathogenetic mechanisms.

\section{Clinical implications and conclusions}

Given the hurdles that riddle the molecular genetics of multifactorial disorders such as myocardial infarction and atherosclerosis, it is surprising in a way that a number of the reviewed studies have yielded "positive results". It is well appreciated, however, that it is much easier to publish a small study with a significant result rather than a large one where no effect on risk is observed, a problem known as "publication bias".

For myocardial infarction, the data suggest protection in carriers of the P selectin Pro ${ }^{715}$ allele and increased risk within specific groups carrying TGF $\beta 1$ and CDI4 variants. For atherosclerosis, the IL Ira intron 2 VNTR alleles may modulate the extent of disease, whereas certain polymorphisms of $\mathrm{E}$ selectin and of PECAM 1 appear to increase the risk, especially in otherwise low risk groups. The association of TGF $\beta 1$ Pro $^{25}$ with myocardial infarction and, conversely, of E selectin Arg $^{128}$, PECAM $1 \mathrm{Val}^{125}$, and IL lra*2 with atherosclerosis raises the possibility that the genetic effects on infarction (possibly through haemostasis or plaque fissure) may be distinct from those on atherosclerosis.

With the advent of DNA microchips, which allow a simultaneous and rapid assessment of multiple genetic variants, ${ }^{51}{ }^{52}$ and with further studies on the functional relevance of the single polymorphism, it should be possible to draw a more accurate profile of the inflammatory gene variants involved in IHD.

\section{Authors' affiliations}

F Andreotti, I Porto, F Crea, A Maseri, Institute of Cardiology, Catholic University, Rome, Italy

\section{REFERENCES}

1 Ross R. Atherosclerosis: an inflammatory disease. N Engl J Med 1999:340:115-26.

2 Woods A, Brull DJ, Humphries SE, et al. Genetics of inflammation and risk of coronary artery disease: the central role of interleukin-6. Eur Heart J 2000;21:1574-83.

3 Ikonomidis I, Andreotti F, Economou E, et al. Increased proinflammatory cytokines in patients with chronic stable angina and their reduction by aspirin. Circulation 1999;100:793-8

4 Herrmann SM, Ricard S, Nicaud V, et al. Polymorphisms of the tumour necrosis factor-alpha gene, coronary heart disease and obesity. Eur J Clin Invest 1998:28:59-66.

5 Padovani JC, Pazin-Filho A, Simoes MV, et al. Gene polymorphisms in the TNF locus and the risk of myocardial infarction. Thromb Res 2000; 100:263-9.

6 Cambien F, Ricard S, Troesch A, et al. Polymorphisms of the transforming growth factor-beta 1 gene in relation to myocardia infarction and blood pressure. The étude cas-temoin de l'infarctus du myocarde (ECTIM) study. Hypertension 1996;28:881-7

7 Yokota M, Ichihara S, Lin TL, et al. Association of a T29 $\rightarrow$ C polymorphism of the transforming growth factor-betal gene with genetic susceptibility to myocardial infarction in Japanese. Circulation 2000;101:2783-7.

8 Manzoli A, Andreotti F, Varlotta C, et al. Allelic polymorphism of the interleukin-1 receptor antagonist gene in patients with acute or stable presentation of ischemic heart disease. Cardiologia 1999;44: 825-30.

9 lacoviello L, Donati MB, Gattone M. Possible different involvement of interleukin-1 receptor antagonist gene polymorphism in coronary single vessel disease and myocardial infarction. Circulation 2000;101:E193.

10 Hubaceck JA, Pit'ha J, Skodova Z, et al. C(-260) $\rightarrow$ T polymorphism in the promoter of the CDI 4 monocyte receptor gene as a risk factor for myocardial infarction. Circulation 1999;99:3218-20.

11 Shimada K, Watanabe Y, Mokuno H, et al. Common polymorphism in the promoter of the CDI 4 monocyte receptor gene is associated with acute myocardial infarction in Japanese men. Am J Cardiol 2000;86:682-4

12 Unckelbach K, Gardemann A, Kostrzewa M, et al. A new promoter polymorphism in the gene of lipopolysaccharide receptor CD14 is associated with expired myocardial infarction in patients with low atherosclerotic risk profile. Arterioscler Thromb Vasc Biol 1999;19:932-8.

13 Zee RYL, Lindpaintner K, Struk B, et al. A prospective evaluation of the CD $14 \mathrm{C}(-260) \mathrm{T}$ gene polymorphism and the risk of myocardial infarction. Atherosclerosis 2001;154:699-702.

14 Herrmann SM, Ricard S, Nicaud V, et al. The P-selectin gene is highly polymorphic: reduced frequency of the Pro7 15 carriers in patients with myocardial infarction. Hum Mol Genet 1998;7:1277-84.

15 Gardemann A, Knapp A, Katz N, et al. No evidence for the CD3 1 $\mathrm{C} / \mathrm{G}$ gene polymorphism as an independent risk factor of coronary heart disease. Thromb Haemost 2000:83:629.

16 Francis SE, Camp NJ, Dewberry RM, et al. Interleukin-1 receptor antagonist gene polymorphism and coronary artery disease. Circulation 1999;99:861-6.

17 Keso T, Perola M, Laippala P, et al. Polymorphisms within the tumor necrosis factor locus and prevalence of coronary artery disease in middle-aged men. Atherosclerosis 2001;154:691-7.

18 Braun J, Marz W, Winkelmann BR, et al. Tumour necrosis factor $\beta$ alleles and hyperinsulinaemia in coronary artery disease. Eur J Clin Invest 1998;28:538-42.

19 Syrris $\mathbf{P}$, Carter ND, Metcalfe JC, et al. Transforming growth factor-beta 1 gene polymorphisms and coronary artery disease. Clin Sci 1998;95:659-67

20 Wang XL, Sim AS, Wilcken DEL. A common polymorphism of the transforming growth factor $\beta 1$ gene and coronary artery disease. Clin Sci 1998:95:745-6

21 Biggart S, Chin D, Fauchon $M$, et al. Association of genetic polymorphisms in the ACE, ApoE, and TGF beta genes with early onset ischemic heart disease. Clin Cardiol 1998;21:831-6.

22 Kastrati A, Koch W, Berger $P$, et al. Protective role against restenosis from an interleukin-1 receptor antagonist gene polymorphism in patients treated with coronary stenting. J Am Coll Cardiol 2000;36 $2168-73$.

23 Wenzel K, Felix S, Kleber FX, et al. E-selectin polymorphism and atherosclerosis: an association study. Hum Mol Genet 1994;3:1935-7.

24 Wenzel K, Ernst M, Rohde K, et al. DNA polymorphisms in adhesion molecule genes: a new risk factor for early atherosclerosis Hum Genet 1996;97 15-20.

25 Ye SQ, Usher D, Virgil D, et al. A Pstl polymorphism detects the mutation of serine 128 to arginine in CD 62E gene: a risk factor for coronary artery disease. J Biomed Sci 1999;6:18-21.

26 Wenzel K, Baumann G, Felix SB. The homozygous combination of Leu $125 \mathrm{Val}$ and Ser563Asn polymorphisms in the PECAM1 gene (CD31) is associated with early severe coronary heart disease. Hum Mutat 1999; 14:545.

27 Azzawi M, Hasleton P. Tumour necrosis factor alpha and the cardiovascular system: its role in cardiac allograft rejection and heart disease. Cardiovasc Res 1999;43:850-9.

28 Wilson AG, Symons JA, McDowell TL, et al. Effects of a polymorphism in the human fumor necrosis factor $\alpha$ promoter on transcriptional activation. Proc Natl Acad Sci USA 1997;94:3195-9. 
29 Blobe GC, Schiemann WP, Lodish HF. Role of transforming growth factor beta in human disease. N Engl J Med 2000;342:1350-7.

30 Nikol S, Isner JM, Pickering JG, et al. Expression of transforming growth factor-beta 1 is increased in human vascular restenosis lesions. J Clin Invest 1992:90:1582-92.

31 Derynck R, Jarrett JA, Chen EY, et al. Human transforming growth factor-beta complementary DNA sequence and expression in normal and transformed cells. Nature 1985;316:701-5.

32 Dinarello CA. Interleukin 1 and interleukin 1 receptor antagonism. Blood 1991;77:1627-52.

33 Santtila S, Savinainen K, Hurme M. Presence of the IL-1RA allele 2 (ILIRN*2) is associated with enhanced IL-1 beta production in vitro. Scand J Immunol 1998;47:195-8.

34 Wright SD, Ramos RA, Tobias PS, et al. CD14, a receptor for complexes of lipopolysaccharide (LPS) and LPS binding protein. Science 1990;249:1431-3.

35 Liao W. Endotoxin: possible roles in initiation and development of atherosclerosis. J Lab Clin Med 1996;128:452-60.

36 Loppnow H, Stelter F, Schonbeck U, et al. Endotoxin activates human vascular smooth muscle cells despite lack of expression of CDI4 mRNA or endogenous membrane CD14. Infect Immun 1995;63:1020-6.

37 Hogg N, Landis RC. Adhesion molecules in cell interaction. Curr Opin Immunol 1993;5:383-90.

38 van der Waal AC, Das PK, Tiggers AN, et al. Adhesion molecules on the endothelium and mononuclear cells in human atherosclerotic lesions. Am J Pathol 1992;141:1427-33.

39 Ikeda H, Takajo Y, Ichiki K, et al. Increased soluble form of P-selectin in patients with unstable angina. Circulation 1995;92:1693-6.

40 Pober JS, Bevilacqua MP, Mendrick DL, et al. Two distinct monokines, interleukin 1 and tumor necrosis factor, each independently induce biosynthesis and transient expression of the same antigen on the surface of cultured human vascular endothelial cells. J Immunol $1986 ; 136: 1680-7$
41 Behar E, Chao NJ, Hiraki DD, et al. Polymorphism of adhesion molecule CD 31 and its role in acute graft-versus-host disease. N Engl J Med 1996;334:286-91.

42 Serebruany VL, Murugesan SR, Pothula A, et al. Soluble PECAM-1, but not P-selectin, nor osteonectin identify acute myocardial infarction in patients presenting with chest pain. Cardiology 1999;91:50-5

43 Johnston GI, Bliss BA, Newman PJ, et al. Structure of the human gene encoding granule membrane protein-140, a member of the selectin family of the adhesion receptors for leukocytes. J Biol Chem 1990;265:21381-5

44 Kee F, Morrison C, Evans AE, et al. Polymorphisms of the P-selectin gene and risk of myocardial infarction in men and women in the ECTIM extension study. Heart 2000;84:548-52.

45 Wenzel K, Stahn R, Speer A, et al. Functional characterization of atherosclerosis-associated Ser $128 \mathrm{Arg}$ and Leu554Phe E-selectin mutations. Biol Chem 1999;380:661-7.

46 Gumina RJ, Kirschbaum NE, Rao PN, et al. The human PECAM1 gene maps to 17q23. Genomics 1996;34:229-32.

47 Strachan T, Read AP. Human molecular genetics. Oxford: BIOS Scientific 1996:499

48 Gambaro G, Anglani F, D'Angelo A. Association studies of genetic polymorphisms and complex diseases. Lancet 2000;355:308-11.

49 Lane DA, Grant PJ. Role of hemostatic gene polymorphisms in venous and arterial thrombotic disease. Blood 2000;95:1517-32.

50 Samani NJ. Molecular genetics of coronary artery disease: measuring the phenotype. Clin Sci 1998;95:645-46.

51 Radtkey R, Feng L, Muralhidar M, et al. Rapid, high fidelity analysis of simple sequence repeats on an electronically active DNA microchip. Nucleic Acids Res 2000;28:E17.

52 Schmalzing D, Belenky A, Novotny MA, et al. Microchip electrophoresis: a method for high-speed SNP detection. Nucleic Acids Res 2000;28:E43.

\section{IMAGES IN CARDIOLOGY}

\section{Misleading appearance of a left atrial thrombus as a cystic mass on transoesophageal echocardiography}

$A^{4}$

42 year old woman was admitted to the emergency department of our hospital with symptoms of dyspnoea and cough. On physical examination her blood pressure was $110 / 70 \mathrm{~mm} \mathrm{Hg}$, pulse 126 beats per minute, and she was arrhythmic. Body temperature was $38.1^{\circ} \mathrm{C}$. An apical diastolic murmur could hardly be heard when the patient was in the left lateral decubitus position. There were fine pulmonary basilar rales. Neither jugular venous distension nor hepatosplenomegaly was present. Peripheral findings of infective endocarditis and Roth spots at fundoscopy were also absent.

Chest $x$ ray demonstrated pulmonary vascular redistribution, parenchymal congestion, and bilateral pleural effusion. Atrial fibrillation was noted on the ECG. A complete blood count revealed anaemia (haemoglobin $6.6 \mathrm{mmol} / \mathrm{l})$ and leucocytosis $\left(18.6 \times 10^{9} / 1\right)$. The erythrocyte sedimentation rate was $55 \mathrm{~mm} /$ hour

Transthoracic echocardiography showed normal left ventricular size and ejection fraction; the mitral valve was fibrotic and calcified, and mitral valve area measured $1.2 \mathrm{~cm}^{2}$, using planimetric and Doppler techniques.

When transoesophageal echocardiography (TOE) was performed a cystic formation was noted in the left atrium, close to the left atrial appendage. It was $21 \times 17 \mathrm{~mm}$ in size and had smooth contours. Nodular structures were visible within the cystic formation. There was also spontaneous echo contrast in the left atrium as shown (LA, left atrium; LV, left ventricle; RA, right atrium; RV, right ventricle; SEC spontaneous echo contrast).

Surgery was performed for mitral valve replacement and removal of the cystic mass in the left atrium. Histopathologic examination confirmed that the mass was a pure thrombus.

M Cemrý

A Erkan

A Cengel

mcemri@hotmail.com

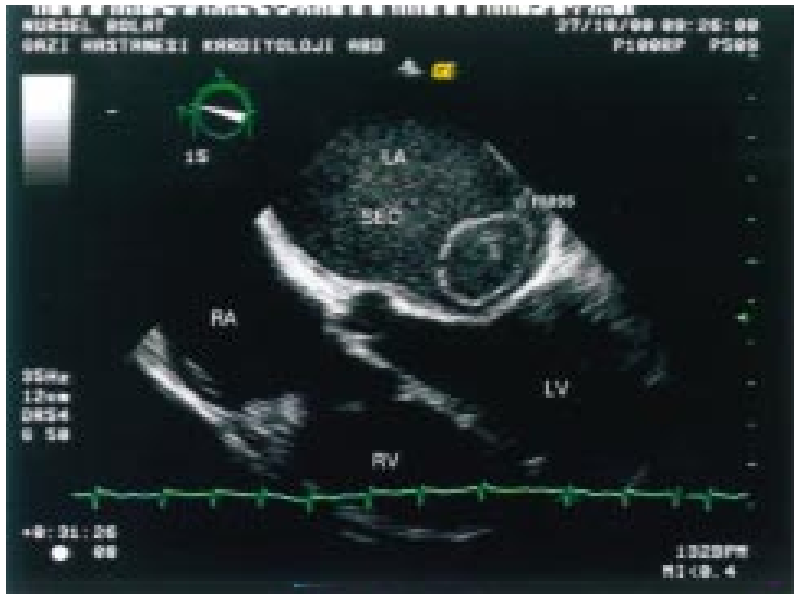

